\title{
ABOUT THE NEED FOR PERFORMING TRAINING AND INCREASING THE QUALIFICATION OF DISPATCHERS AND MOVEMENT MANAGERS IN RAILWAY TRANSPORT
}

\author{
${ }^{1}$ Dimitar Dimitrov Associate prof., Dr. Eng., \\ ${ }^{2}$ Zlatin Trendafilov Senior Lecturer. Dr. Eng. \\ Bulgaria, Sofia, 'Todor Kableshkov' University of Transport, Department 'Technology, Organization \\ and Management of Transport'
}

DOI: https://doi.org/10.31435/rsglobal_ijite/01062018/5677

\author{
ARTICLE INFO \\ Received 28 April 2018 \\ Accepted 26 May 2018 \\ Published 01 June 2018

\section{KEYWORDS} \\ transport, \\ traffic, \\ railway infrastructure, \\ dispatching system, \\ train movement management, \\ information systems
}

\begin{abstract}
The modern movement of trains in railway transport is a high-tech process related to the management of their movement through modern technical and information systems. The construction and modernization of these systems is cyclical and usually coincides with the rehabilitation and modernization of railway transport. These systems mainly employ mid and high management staff, namely traffic managers and train dispatchers of the respective railway sections. This publication discusses the contemporary aspects and perspectives for carrying out professional training and enhancing the qualifications of traffic managers and train dispatchers in railway transport. In fulfilling this objective, the functional characteristics, parameters and capabilities of the implemented concrete systems are taken into account, namely the company "TALES", which has implemented several projects in Bulgaria in recent years.
\end{abstract}

(C) 2018 The Authors.

Introduction. The efficient operation of railway transport is of particular importance for carrying out the necessary passenger and freight transport. On the one hand, this is a top priority in terms of forecasting and planning of the transport process, and on the other hand it is related to real traffic and traffic management. This also includes the particularly important operation-related activity related to the management and control of traffic on the railway network $[1,2]$.

The modern movement of trains in railway transport is a high-tech process related to the management of their movement through modern technical and information systems. The construction and modernization of these systems is cyclical and usually coincides with the rehabilitation and modernization of railway transport. Cyclicality stems from the stepwise development and rehabilitation of infrastructure, and the life of these systems is reduced and resumed during smaller periods of operation of the systems themselves, as the rapid development of information and telecommunication systems is the cause. These systems mainly employ mid and high management staff, namely traffic managers and train dispatchers of the respective railway sections. They use them in the so-called dispatch centers, where the management processes for the provision of train movements and maneuvering at stations are centralized, as well as signaling management, station centralization and the blocking of unregulated actions and processes [3, 4]

This publication discusses the contemporary aspects and perspectives for carrying out professional training and enhancing the qualifications of traffic managers and train dispatchers in railway transport. In fulfilling this objective, the functional characteristics, parameters and capabilities of the implemented concrete systems are taken into account, namely the company "TALES", which has implemented several projects in Bulgaria in recent years. Particular attention is paid to multimedia training and the need to build a simulation base to simulate real processes connected with management, train movement provision and shunting activity at stations.

Model for provision of railway transport management. The management of the railway transport processes includes management activities and tasks for the safe and timely provision of the necessary rolling stock, its loading for the passengers (respectively the embarkation of the passengers), the movement on the respective route as well as the unloading of the passengers (disembarkation of the passengers) and leaving the transport system. This is a complex process and requires a high degree 
of consistency and synchronization of transport processes, while at the same time requiring simplicity and easy orientation for passengers and customers of transport services. [5, 6]

For example, it is important for railway companies to meet the following requirements and tasks [7, 11]:

- Ensuring the use of railway infrastructure by licensed carriers on a level playing field;

- Carrying out activities related to the development, repair, maintenance and operation of the railway infrastructure;

- Collection of the relevant infrastructure charges;

- Development of train timetables coordinated with carriers and for passenger transport - and with municipalities;

- Train management of railway infrastructure in compliance with safety, reliability and safety requirements;

- Acceptance of all transport requests by carriers;

- Acceptance and execution of all requests arising from public service obligations;

- Preparation, maintenance and storage of a register that contains land and railway infrastructure data;

- Implementation of the investment policy for the development and modernization, maintenance and repair of the railway infrastructure for realization of the required criteria and standards.

The Master Traffic Management Plan is governed by the Train Traffic Schedule (TTS), which is a detailed plan for the movement of all trains on the railways. It determines the amount of movement in the number and category of trains for each section. They agree on the arrival and departure of trains at the nodal stations and their movement along the railway sections. It is the basis for ensuring safety and security in rail transport. The TTS determines not only the movement of trains but also the operation of all divisions. It binds the entire transport network to a single whole and therefore has organizational significance for the operation of the railways (infrastructure and carriers).

The implementation of the train traffic timetable is realized through a centralized system for dispatching and controlling the traffic processes in the sections of the railway network. The movement of trains and other railway vehicles is managed by train dispatchers through station supervisors at the stations. [8]

The work of the train dispatchers. The main task of the dispatching management is to ensure traffic safety and to prevent the work at stations, depots, sections and others in the railway section as a whole. The train dispatcher normally controls the movement of the trains in its assigned area. It is operationally subordinate to the Chiefs of Offices and Heads of Movement at the stations and divisions, the carriers, the locomotives and the transport crews operating in its section, as well as the staff working on the maintenance of the railway infrastructure and all other workers and employees concerned with transport safety.

The train dispatcher on his/her duty is a sole authorized officer for the movement of trains in his/her area, ensuring accurate and safe passage of trains, and, in the event of disturbances and traffic disruption, co-organizes train movements.

To exercise permanent control over the movement of trains, the train dispatcher conducts a working schedule for the actual realization of the approved TTS in its assigned area. All the information he receives from the various staff and services is necessary for him to make correct and timely operational decisions to regulate the movement of trains, to prevent possible violations of the schedule, to adhere strictly to the rules for safe passage of railway vehicles at stations and interconnections. He/She has to get acquainted with the upcoming train timetable, paying particular attention to the damage to the safety equipment at stations and interchanges and the operating mode of the stations, the occupied recruitment routes, newly assigned and reduced trains in the section, their location in and the presence of trains carrying special cargoes, long-drawn trains, etc.

To ensure the safe passage of railway vehicles in stations and interchanges, the train dispatcher has the right to modify the points and the order of diverting, overtaking and passing the trains, to speed up their movement by creating the best possible conditions for skipping, shortening the stops of the trains, organizes the proper use of breaks in the station and stations due to repair and restoration work, accidents and others.

The senior train manager plans the operation for the next 24 hours according to the requests of the carriers, preparing and issuing an order for the train work for the area under his care. The order is issued in compliance with the requirements of the regulations for the appointment and cancellation of trains. Planning of the operation via the railway stations (the border stations where the transmissions and the acceptance of the trains between the various units are carried out). The Senior Train 
Dispatcher - on shift, during his duty, manages and supervises the work of the train dispatchers in the shift. He/she is obliged to:

- integrate the work of train dispatchers;

- control and coordinate the movement of trains through border and railway stations;

- participate, make suggestions and take decisions at meetings with the dispatch center for operational work, and attend the meetings of the railway carriers with the train stations;

- resolve difficulties encountered in the operation of train dispatchers;

- exercise control over the operation of the train dispatchers according to the instructions given by them in relation to the train traffic control and the technical condition of the devices of the insurance equipment; infrastructure;

- comply with the requirements for equal treatment of all licensed carriers to the railway

- fulfill the duties assigned to him/her, in accordance with the rules governing the movement of trains.

Through the dispatching management of trains, the following important tasks are also provided:

- dispatch control and control of train movements along railway lines and nodal stations;

- technical control on the condition of railways;

- central data processing for the system;

- processing of violations in the exploitation process;

- central storage and processing of train running time data;

- dispatch control on the railway network;

- analysis of the operation process and distribution of the information about it.

Workspaces of train dispatchers are concentrated in dispatch halls, and action zones are geographically formed - the so-called Dispatching Circles. The dispatcher workstations are equipped with tracking monitors, railway points (switches), showing busy or unoccupied tracks, a time/route diagram, etc.. An opportunity to print the operational processes is provided. Various specialized keyboards are provided for the different systems - dispatching, stationary, telecommunication. All conversations and orders related to train traffic management and stopping of movement, crashes, accidents and other information between train dispatchers, senior train dispatchers and traffic managers (movement managers) are generally conducted under dispatching system.

During the implementation of the transport process and the movement of the trains on schedule, the schedules of the carriers, the railway maintenance dispatchers, the energy dispatchers, etc. are also included. They may have different zoning than the train dispatcher circles.

Overview of the functional parameters of dispatching management systems and deployed solutions. The construction of modern dispatching systems in rail transport generally consists of a combination of diagnostic devices and sensors, controllers for controlling devices (switches, signals, train control systems, etc.), communication networks and communication devices, computer systems and servers) that work in sync and enable the train manager to manage and control the processes of route and train management through the analytical and visual components of the system when provided nominal mode of security and safety of the various subsystems, components and movement of rolling stock.

The basic requirements for modern vehicle transport management systems are based on the following requirements [8] and scope of solved tasks, namely:

- detailed location of the vehicles in time and space depending on the speeds and requirements for safe movement;

- the transmission of detailed information between the vehicles and the link to the centralized traffic management system;

- the transmission of detailed information between the traffic management system and the other services involved in ensuring the movement of the means of transport;

- possibility to determine changes as necessary and to control the routes of the means of transport;

- running predicted routes and conflicts as well as quickly restoring movement to normal parameters;

- optimizing routes to reduce fuel and time consumption, including shortening the idle mileage;

- reporting and transmission of information on certain parameters of the means of transport (fuel, operation of security systems, etc.);

- control and awareness of freight and passengers in the means of transport, their delivery to the destination endpoint;

- other features relating to transport, means of transport, the environment, etc. 
The degree of automation of individual aggregates and devices in transport vehicles (rolling stock) related not only to traffic and security but also to the creation of a good environment is also a task that has recently been seriously evolving and progressing. $[9,10]$

In Bulgaria, with the development and rehabilitation of the main railway sections [11], such information systems are being implemented. Thales Austria is primarily concerned with their construction [12]. Figure 1 shows the map showing the main railway sections that have been constructed so far:

- Plovdiv - Burgas: ETCS L1 on the country side + On-Board;

- Sofia - Karlovo rehabilitation;

- Plovdiv - Svilengrad: Electronic centralization, ETCS L1, Traffic Control and Service Center, Telekom, GSM-R;

- Plovdiv - Burgas construction project: axle counters, railway switches;

- Sofia / September - Plovdiv: Electronic centralization, ETCS L1, Telekom, GSM-R.

Figure 2 shows a common view of a command control room for controlling train movements.

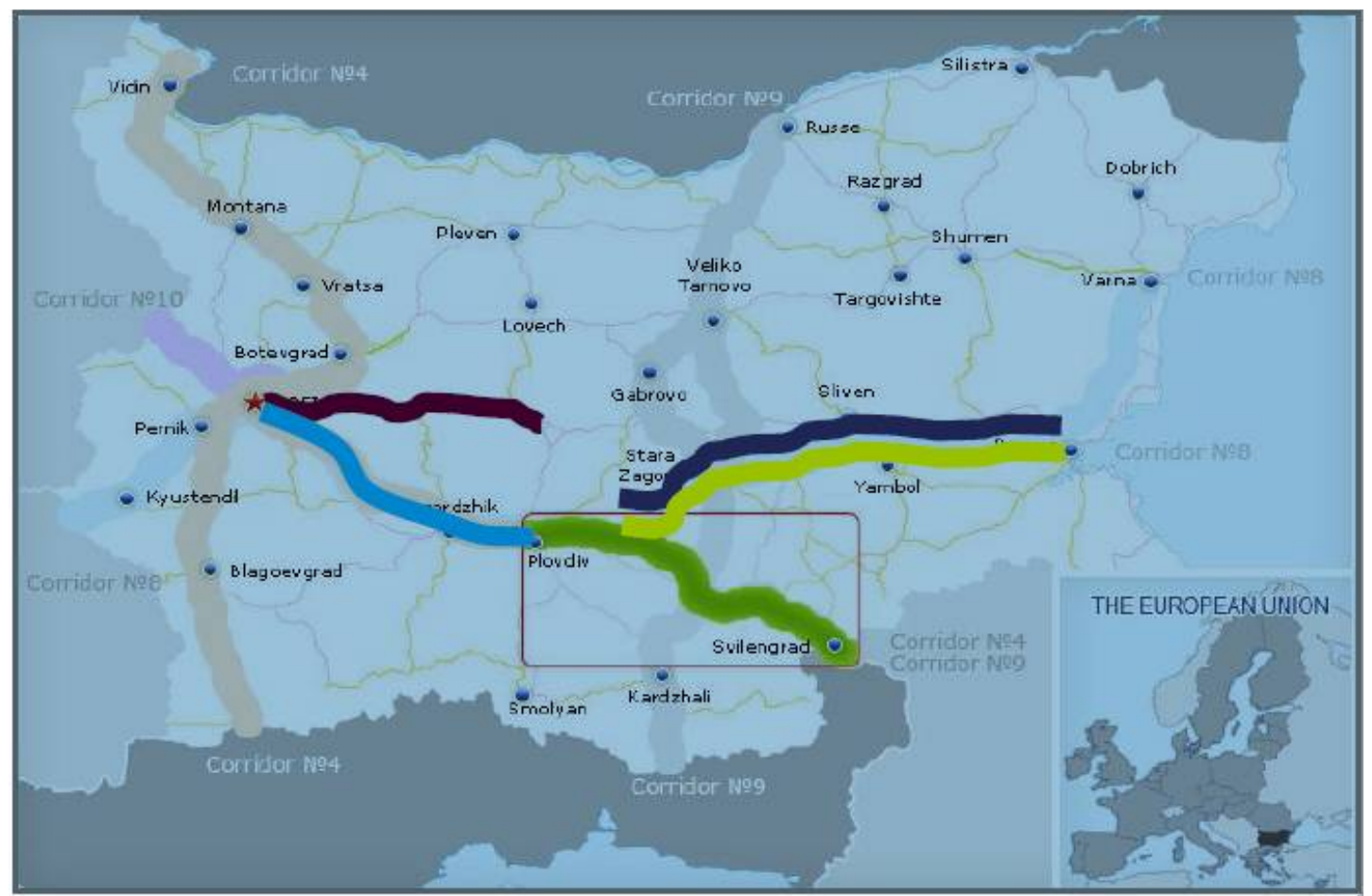

Fig. 1. Main railway projects of Thales Austria in Bulgaria

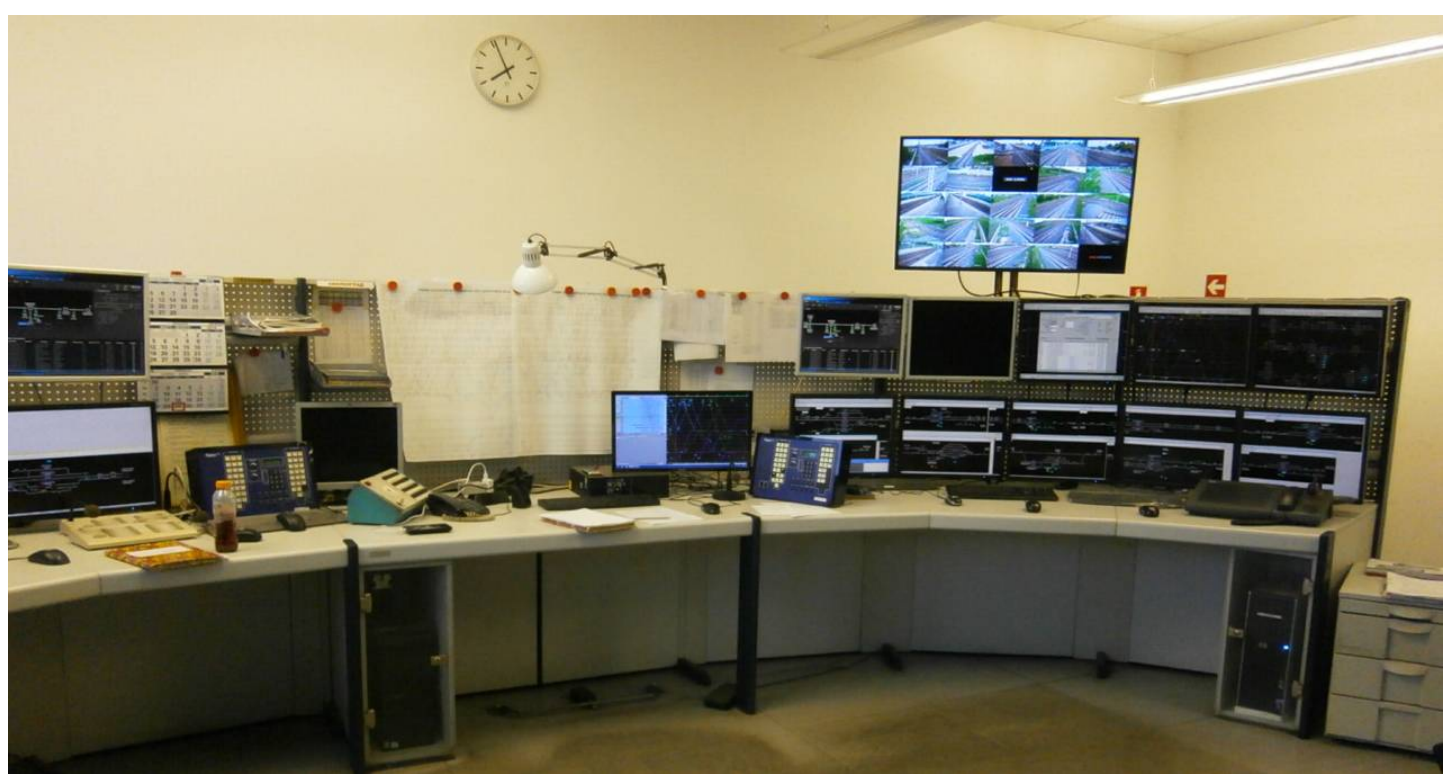

Fig. 2. General view of a command control room for train control 
Using the dispatch management systems in training. As it has become known, dispatch management is a complex task in terms of the logic of the train running processes, as well as the design of such a system as hardware and software. Although the interface of these systems is contextoriented and relatively easy to operate with the systems themselves, its volume makes it sophisticated to work when there is no practical training to work with the system.

Qualified training with systems is an important task, which should be of a periodic nature and related to testing and certification of learners. In this connection it is necessary, along with the manufacturer and the training center to be built and implemented simulator training and testing and certification of personnel working in these dispatch centers and for students involved in controlling the movement of trains in the railway transport.

In extreme situation, dispatching system, even as modern and sustainable process for ensuring the safety on first place in the movement of trains, can be discredited and made vulnerable, and the people running it must be fully prepared to tackle the situation both in a crisis situation and in the normal mode for its operation.

Last but not least, can mentioned the creation of so-called multimedia and interactive training to work with these systems, which would lead to the skills and automatism of the actions of the learners, similar to multimedia games and entertainment, that for good or for bad is the current reality of life in recent years..

Conclusions. The present paper discussed the issues of professional training and qualification of traffic managers and train dispatchers in rail transport.

In this regard, the issues concerning the specificity of the work of the train dispatchers, as well as this activity in general, which is related to the operational management of the railway transport, were addressed. An overview of the functional parameters of the dispatching systems was presented, as well as the implemented solutions in our country for rehabilitated and modernized sections of the railway network.

Considering the complexity of the process of organizing the dispatching management as well as the complexity from the point of view of the construction of such real-time information systems, methodological recommendations were made on the necessity of building a training complex for training, testing and certification of workers and new- frames.

Special attention was paid to multimedia training and the need to build a simulation base to simulate real processes ensuring management, exploitation and maneuvering activities in railway stations.

\section{REFERENCES}

1. Raikov R., Organization and management of the railway transport. S., VMEI, 1985

2. Raykov R., Georgiev N., Stoikov D., Berov T., Stoyanov I. Technical exploitation and safety of transport. "Todor Kableshkov" University of Transport, Sofia. 2002.

3. Stoilova S. Organization and Management of Railway Transport, MP Publishing House of TU - Sofia, 2010

4. Razmov T. Methodology, modelling and traffic forecasts and investments needed of ERTMS implementation into the railway network of Bulgaria, S. S. H. B. Czech Telematic Autumn in Bulgaria, Ed. 2008

5. Dimitrov D., Kirchev T. Task for Operational Management of Transport Posts, Collection of Reports of the 15th Scientific Conference with International Participation TRANSPORT-2005, I-59-I-62

6. Dimitrov D., Kirchev T. Modeling of the Train Controller's Work in Traffic Management in Railway Transport, Collection of Reports of the Twelfth Scientific Conference with International Participation TRANSPORT-2002, pp. 73-76

7. Kirchev T., Modeling and Traffic Management in Operational Conditions, Todor Kableshkov University of Transport, Sofia, 2017 (http://www.vtu.bg/wpcontent/uploads/2017/12/avtoreferat_Kirchev.pdf)

8. Dimitrov D., Kirchev T., Application of Modern Information Tools in an Operational Transport Management, Mechanics, Transport, Communications, Academic journal, ISSN 1312-3823, Volume 11, Issue 3, 2013, Article No 0783 (http://mtc-aj.com/library/783.pdf)

9. http://www.railway-research.org/

10. http://tout.vtu.bg/project/dicpactchsystemtransport_NEW.htm

11. http://www.rail-infra.bg/

12. http://www.thalesgroup.com/ 